\title{
Fixed Prices and the Direct Support Professional Workforce Crisis
}

\author{
Scott Spreat \\ Woods Services Research Institute, Langhorne, USA \\ Email: sspreat@gmail.com
}

How to cite this paper: Spreat, S. (2021). Fixed Prices and the Direct Support Professional Workforce Crisis. Open Journal of Social Sciences, 9, 158-166.

https://doi.org/10.4236/jss.2021.91011

Received: December 9, 2020

Accepted: January 15, 2021

Published: January 18, 2021

Copyright $\odot 2021$ by author(s) and Scientific Research Publishing Inc. This work is licensed under the Creative Commons Attribution International License (CC BY 4.0).

http://creativecommons.org/licenses/by/4.0/

\begin{abstract}
The current Direct Support Professional workforce crisis was considered from the perspective of supply/demand economic theory. It is suggested that the workforce crisis is largely caused by the inability of provider agencies to balance the demand for and supply of Direct Support Professionals by manipulating wages. Governmental fixed prices for supports and services are suggested as a primary contributing factor.
\end{abstract}

\section{Keywords}

Intellectual Disability, Workforce Crisis, Direct Support Professional, Supply \& Demand

\section{Introduction}

The Intellectual Disability/Autism field cannot hire a sufficient number of qualified Direct Support Professionals to meet the demand. These are individuals who provide direct support, training, and care for individuals who have intellectual disability and/or autism. The National Core Indicator (2018) project reported an 11.2\% vacancy rate for full time Direct Support Professionals and a $15.9 \%$ vacancy rate for part time Direct Support Professionals. More recent research (Spreat, 2019a) suggests that as many as one in five (19.4\%) Direct Support Professional positions in Pennsylvania were vacant, and that annual pre-pandemic turnover approached $40 \%$. A workforce crisis has been publicly pronounced by both the American Association on Intellectual and Developmental Disabilities (2016) and the President's Committee on People with Intellectual Disabilities (2012). While one may argue whether what is a long standing staffing problem is properly called a "crisis" (Hewitt, 2013), it is clear that agencies that support individuals who have intellectual disability are challenged to hire sufficient numbers of com- 
petent staff.

Some contributing factors to this workforce crisis may be longer life spans for people with intellectual disability, the increasing support needs of the aging Baby Boomer generation, and the current availability of better paying jobs. One might also note that group homes, the dominant residential model in the intellectual disability industry since 1991 (Conroy, 2017), tend to be more labor intensive in terms of Direct Support Professionals than many state developmental centers. Less frequently mentioned as a significant contributing factor is the practice of governmental agencies setting, or fixing, the price they will pay for Intellectual Disability supports and services.

Fixed prices for supports and services limit the ability of social service agencies to respond to market conditions in order to attract more staff. Note that intellectual disability service provider agencies already operate on an unhealthy $1.0 \%$ to $1.5 \%$ margin between revenue and expenses (Spreat, 2019a). With increasing demand for Direct Support Professionals, agencies have little flexibility to economically respond to this increased demand by raising wages. They are unable to respond to market conditions. In economic theory, price (in this case, wages) is supposed to create equilibrium between supply and demand (Pettinger, 2017). When demand is high, prices must go up if needs are to be met. When price is constrained in any way, shortages will result. Under the government controlled price model, shortages of Direct Support Professionals should hardly be surprising.

It should be noted that while governments set the prices that they will pay for supports and services, they do not set the wage that a provider must pay Direct Support Professionals. The hourly wage is free to vary within the budgetary constraints of the provider agency. These constraints, however, do place strong effective limits on what a provider can pay a Direct Support Professional. Provider agencies currently tend to devote $75 \%-85 \%$ of their budgets to staff compensation, and with the unhealthy operating margin reported above, there is little room for a provider agency to adjust compensation to attempt to balance the supply of Direct Support Professionals with the demand for them. Governmental agencies do not set the wages for Direct Support Professionals, but their payment practices effectively limit what a provider agency can pay Direct Support Professionals. These pricing practices are significant contributors to the workforce crisis.

Spreat (2019b) recently reported a mean hourly wage of $\$ 12.83$ for Direct Support Professionals in Pennsylvania. Torres, Spreat, \& Clark (2017) reported that many Direct Support Professionals earn so little money that they qualify for many forms of government welfare. Efforts to increase Direct Support Professional pay have focused on the concept of a "living wage" for Direct Support Professionals. This approach may be utilitarian because it lends an emotional element to the appeal, but it must be recognized that even if rates were to be increased to the level of a "living wage" today, the continued practice of fixing prices by the government is likely to ensure that the same problem of a workforce crisis will emerge 
eventually. One must also recognize that a "living wage" might not be the wage that establishes equilibrium between supply and demand. It may be insufficient to fill positions, or it may constitute an overpayment.

The dependent measure of interest should be the number of open positions rather than the hourly wage. Open positions jeopardize the welfare of the people that provider agencies are pledged to support and serve. Price (i.e., wages) is supposed to be the mechanism that creates a balance between supply and demand for the workforce. In the Intellectual Disability/Autism field, the problem is that while wages have generally kept up with inflation (Spreat, 2020), demand has increased at a greater rate. Wages need to be increased to achieve equilibrium between the supply of Direct Support Professionals and the demand for Direct Support Professionals. More importantly, prices must be freed to respond to market demands, rather than constrained by governmental pricing practices.

Much of the research on the intellectual disability workforce has focused on the hourly wage paid to Direct Support Professionals rather than the issue of vacant positions. This is understandable given the empirical linkage between hourly wage and turnover (Larson, Lakin, \& Bruininks, 1998). Early research (Braddock \& Mitchell, 1992) reported a mean hourly wage of $\$ 5.97$ for Direct Support Professionals who worked in community settings. At this time, the mean hourly wage in the United Stated was \$ 10.79 (Data 360, undated). In subsequent research, Durgin (1999) reported a mean hourly wage of \$ 8.13 among Pennsylvania Direct Support Professionals in 1999. Hewitt, Larson, \& Lakin (2000) reported an hourly wage of $\$ 8.81$, and Polister, Lakin, \& Prouty (2003) reported a comparable \$ 8.68 per hour. An ANCOR (2009) study reported a mean hourly wage of $\$ 10.14$. Subsequent to the 2008 recession, Bogenschutz, Hewitt, Nord, \& Hepperlen (2014) reported an annual wage of \$ 11.26. Clearly, hourly wages have increased over time for Direct Support Professionals, and this increase modestly exceeded inflation (Bureau of Labor Statistics, 2013). Despite this increase, Direct Support Professionals are paid less than a "living wage," many qualify for welfare (Torres, Spreat, \& Clark, 2017), and more importantly, positions appear to be increasingly vacant.

The number of vacant Direct Support Positions has been a secondary variable in a number of studies, but the concern is frequently cited in lobbying efforts. In 2000, Hewitt, Larson, \& Lakin (2000) reported an $8.2 \%$ vacancy rate among Direct Support Professionals. A national survey (ANCOR, 2001) reported a vacancy rate among Direct Support Professionals of $10.8 \%$. More recently, the National Core Indicator project (NCI, 2019) reported an $11.2 \%$ vacancy rate among Direct Support Professionals in a multi-state survey of staff stability (ranging from $5.5 \%$ to $15.9 \%)$.

In Pennsylvania, a consortium of seven Intellectual Disability provider associations (Moving Agencies toward Excellence, Pennsylvania Advocacy and Resources for Autism and Intellectual Disability, Rehabilitation and Community Providers Association, The Alliance of Community Service Providers, The Arc 
of Pennsylvania, The Provider Alliance, and United Cerebral Palsy of Pennsylvania) jointly sponsored a series of four Direct Support Professional compensation surveys. These surveys were conducted over the years 2015 to 2019. The number of agencies that responded to each survey varied from year to year, with an average of 153 agencies each year. These agencies employed a total of over 30,000 Direct Support Professionals. This figure is believed to represent roughly one half of the Direct Support Professionals working in the intellectual disability industry in Pennsylvania.

The four surveys reported data on open positions, turnover, benefits, and hourly wages. Of particular interest is the number of open positions, as reported by the responding agencies. Open positions were calculated by dividing the number of open or unfilled positions by the number of filled positions plus the number of open positions. The provider agencies reported a 10.6\% vacancy rate in 2015 (Spreat, McHale-Brown, \& Walker, 2017), a 12.0\% vacancy rate in 2017 (Torres, Spreat, \& Clark, 2017), a 20.4\% vacancy rate in 2018 (Spreat, 2018), and a 19.4\% vacancy rate in 2019 (Spreat, 2019b).

Larson, Lakin, \& Bruininks (1998) earlier reported that turnover was largely a function of low pay. To test this hypothesis on the vacancy variable, we performed a median split on hourly wage. We then compared the vacancy rates for high and low paying providers. Using just the 2018 data (highest vacancy rate), we found no significant difference; the mean vacancy rates were just 1/100 apart.

\section{Discussion}

The four studies suggest that the vacancy rate for Direct Support Professionals is worsening over time, lending considerable credence to the subjective impressions voiced by many providers that things are worsening. Being both current and large in sample size, the 2019 survey that yielded a $19.4 \%$ vacancy rates is perhaps the best representation of current conditions.

Based on the large 2019 sample representing 36,081 Pennsylvanians employed as Direct Support Professionals, almost 20\% of Direct Support Professional positions are vacant in Pennsylvania. Let us consider the fiscal impact of the 20\% vacancy rate. The most significant implication is that at least $20 \%$ of all required hours must be filled with overtime being typically paid at $150 \%$ of the mean hourly wage. The mean hourly wage for a Pennsylvania Direct Support Professional was $\$ 13.30$ (Spreat, 2019b) \$13.30; overtime rate would then be $\$ 19.95$. Total wages if no overtime was needed to fill vacancies would be calculated by mean hourly wage $(\$ 13.30)$ time total number of Direct Support Professionals (estimated 55,000) times 2080 hours (full year full time). This calculation would project costs to be $\$ 1,521,520,000$ per year. If $20 \%$ of those hours (i.e., 11,000 times 2080) had to be filled at the overtime rate of $\$ 19.95$, additional costs to Pennsylvania would be approximately $\$ 149$ million per year, an increase of about $10 \%$ over straight time. Note that this does not count time off for vacation, sick leave, family medical leave, or training. As Torres, Spreat, \& Clark (2017) noted, 
it might be cheaper to pay Direct Support Professionals a better hourly wage.

Focusing solely on fiscal matters is overly limited. Recognize that the intellectual disability industry is based largely on the development of supportive relationships with the individuals being assisted. The development of relationships becomes challenged when the demand to fill vacancies with available staff. One Philadelphia provider CEO recently reported at a provider association meeting that one individual she supports was bathed and/or toileted by 35 different people over the previous month. Relationships are shortchanged, program continuity is threatened, and quality of life is jeopardized by this excessive use of overtime.

The issue isn't simply that the wages paid to Direct support Professionals are too low. The issue is that providers do not have the flexibility to respond to changing market conditions. They are forced to use excessive amounts of overtime, and they become less selective in their hiring practices. Their inability to respond to changing market conditions is a direct result of government fixed prices that constrain the providers from responding to changing market conditions.

The Direct Support Professional workforce has been in crisis for many years, and the problem seems to be worsening. Four basic strategies warrant consideration. They are 1) seek additional funding levels, 2) reduce the costs of services, 3) develop alternative funding strategies, and 4) creative recruitment. Each will be discussed below.

Seek additional funding levels-Service and supports for individuals who have intellectual disability have been systematically underfunded over the past several decades. Spreat (2020) reported that while the spending in the Pennsylvania general budget increased over $90 \%$ over the past 20 years, spending on intellectual disability services increased only $23 \%$. It is clear that advocates have not made it in the interest of legislative bodies to ensure sufficient funding for intellectual disability services. Despite the observations of former Philadelphia congressman Ozzie Meyers during the Abscam scandal, the generation of legislative interest can be done legally through Political Action Committees. Most non-profit agencies expect senior staff to make some sort of donation (typically around 1\%) back to the agency. Perhaps the money would be better spent if given to a Political Action Committee that could use the money to generate increased levels of legislative support for intellectual disability services.

An alternative strategy with which to seek additional funding would be litigation. Unfortunately, this has not been a successful strategy, with the Supreme Court finding that provider agencies did not have the standing to sue state agencies over funding levels (Armstrong v. Exceptional Child Center, 2015).

Reduce costs of services-It must be recognized that operating a group home is an expensive endeavor. Annual costs per consumer in excess of $\$ 100,000$ are not unusual. Life Sharing is a relatively new program offering that offers significant savings for some individuals. Life sharing involves an individual with intellectual disability moving in with a host family. The host family is paid for pro- 
viding support to that individual. In a sense, Life Sharing is a form of adult foster care, and it is considerably less expensive than group home models. Life sharing has yet to be submitted to a thorough empirical evaluation, as was the group home model.

Costs might also be reduced by a closer review of the regulations under which most residential and day service programs operate. When introduced, regulations for the intellectual disability field were designed to ensure health and safety, but not necessarily quality. They now dictate almost all activities of providers. Certainly, a reduction in regulations could result in some savings that could help reduce the workforce crisis.

Alternative Payment Models-Alternative Payment Model typically include program funding, fee for service, pay for performance, and managed care models. Most models seem to introduce additional layers of bureaucracy without creating any significant savings. They simply alter how an insufficiently sized pie is to be cut. There is one alternative payment model that has been empirically demonstrated to save somewhere between $5 \%$ and $15 \%$. Introduced on Monadnock, New Hampshire, self directed funding places control for service dollars in the hands of the consumer and his/her circle of friends and family. They purchase what they believe they need. Conroy, Yuskaukas, and Spreat (2020) demonstrated that this approach resulted in modest savings. Their study was, however, little more than a pilot study, and additional empirical support would be needed to justify any widespread adoption.

Creative recruitment strategies-Diamond and Drummond (2020) identified a number of low cost recruitment and retention strategies that may make the Direct Support Professional program more attractive to applicants. Direct Support Professionals are offered undergraduate or graduate tuition in return for a promise to remain in the employment of the provider. Programs developed include Nursing, Masters in Human Services, as well as Bachelors and Associates general programs. This is essentially an indentured service model, in which the Direct Support Professional gets free or reduced cost education in return for a promise to remain in the position for a mutually agreeable period of time. Ultimately, the Diamond and Drummond (2020) strategies will drive Direct Support Professionals from the position, but they may reduce the immediate crisis. The success of these strategies remains to be established.

\section{Conclusion}

It seems reasonable to suggest that the governmental practice of fixing the price for intellectual disability supports and services is at least contributory to the contemporary Direct Support Professional workforce crisis. The long standing practice of systematically underfunding intellectual disability supports and services prevents providers from being able to achieve equilibrium between the demand for Direct Support Professionals and the supply of Direct Support Professionals.

It seems unlikely that governmental agencies will discontinue the practice of 
fixing prices, and it seems equally unlikely that systematic underfunding patterns will cease. It has been suggested that the passing of the Baby Boomer generation will ease some of the economic challenges. It seems unlikely that the intellectual disability industry will be permitted to become part of a free market, and it appears unlikely that significant rate adjustments will improve the workforce crisis. Alternate strategies will be needed. This challenging situation provides the framework for the growing popularity of the Life Sharing (adult foster care) model that may be able to offer satisfactory supports and services for a reduced cost to at least a portion of the intellectual disability population.

A sobering final thought-the systematic underfunding of intellectual disability services creates a situation in which the poorest paid employees in the system are essentially subsidizing the operation of the programs. This doesn't happen with the construction of bridges and highways. Money that should be paid to Direct Support Professionals is going to subsidize underfunded programs. This cost diversion is another expected outcome of fixed prices (Pettinger, 2017).

It must be recognized that this analysis was based on data collected in a single state, and one cannot confidently extrapolate these findings to other states. Projections of the mean hourly wage were based on about $65 \%$ of the projected number of Direct Support Professionals in Pennsylvania. An actual count of the number of Pennsylvania Direct Support Professionals is not available. Perhaps the greatest limitation of this paper is that the relationship between supply, demand, and pricing is theoretical rather than lawful. It must be understood that Economics is a soft science.

\section{Conflicts of Interest}

The author declares no conflicts of interest regarding the publication of this paper.

\section{References}

American Association on Intellectual and Developmental Disabilities (2016). Position Statement on the Direct Support Professional Workforce. Washington DC: American Association on Intellectual and Disabilities.

ANCOR (2001). Results of ANCOR Staff Vacancy/Turnover Survey. Annandale, VA: ANCOR.

ANCOR (2009). Direct Support Professional Wage Study. Alexandria, VA: ANCOR.

Armstrong v. Exceptional Child Center (2015). Washington DC: United States Supreme Court, Decided 3/31/15.

Bogenschutz, M., Hewitt, A., Nord, D., \& Hepperlen, R. (2014). Direct Support Workforce Supporting Individuals with IDD: Current Wages, Benefits, and Stability. Intellectual and Developmental Disabilities, 52, 317-329. https://doi.org/10.1352/1934-9556-52.5.317

Braddock, D., \& Mitchell, D. (1992). Residential Services and Developmental Disabilities in the United States: A National Survey of Staff Compensation, Turnover, and Related Services. Washington, DC: AAMR.

Bureau of Labor Statistics (2013). http://www.bls.gov/oes/current/oes nat.htm\#31-0000 
Conroy, J. W. (2017). Threshold of Liberation: The Little Known History of Deinstitutionalization of Americans with Developmental Disabilities in the Late 20th Century. Pennsylvania Legacies, 17, 26-31. https://doi.org/10.5215/pennlega.17.2.0026

Conroy, J., Yuskauskas, A., \& Spreat, S. (2020). Outcomes of Self-Determination in New Hampshire. Social Innovations, 60, unpaginated. http://www.data360.org/dsg.aspx?Data Set Group Id=773\&count=all

Diamond, D., \& Drummond, E. (2020). Alternative Approaches to Recruitment and Retention. Social Innovations, 60, Unpaginated.

Durgin, P. (1999). Salary Levels and Their Impact of Quality of Care for Client Contact Workers in Community Based MH/MR Programs. Harrisburg, PA: Legislative Budget and Finance Committee of the General Assembly.

Hewitt, A. (2013). Raising Expectations: The Direct Support Professional Workforce. The Arc National Conference, Seattle, 4 August 2013.

Hewitt, A., Larson, S., \& Lakin, C. (2000). An Independent Evaluation of the Quality of Services and System Performance of Minnesota's Medicaid Home and Community Based Services for Persons with Mental Retardation and Related Conditions. Institute on Community Integration, Minneapolis: University of Minnesota.

Larson, S., Lakin, C., \& Bruininks, R. (1998). Staff Recruitment and Retention: Study Results and Intervention Strategies. Washington DC: AAMR.

National Core Indicators (2018). Snapshot of Direct Support Workforce Challenges in the United States.

https://www.nationalcoreindicators.org/upload/coreindicators/1 DSP workforce chall enges whole.pdf

Pettinger, R. (2017). Price Controls-Advantages and Disadvantages. https://www.economicshelp.org/blog/621/econonics/price-controlsadvantages-and-dis advantages/

Polister, B., Lakin, K., \& Prouty, R. (2003). Wages of Direct Support Professional Service Persons with Intellectual and Developmental Disabilities: A Survey of State and Private Residential Provider Trade Associations. Research and Training Center of Community Living, Institute on Community Integration, College of Education and Human Development, University of Minnesota, Volume 14.

President's Committee on People with Intellectual Disabilities (2012). Managed Long Term Services and Supports: 2012 Report to the President. Washington DC: President's Committee on People with Intellectual Disabilities.

Spreat, S. (2018). Pennsylvania Direct Support Professional Wage Study. Langhorne, PA: Alliance of Community Service Providers (ACSP), Moving Agencies toward Excellence (MAX), Pennsylvania Advocacy and Resources for Autism and Intellectual Disability (PAR), Rehabilitation and Community Providers Association (RCPA), Arc of (Arc/PA), The Provider Alliance (TPA), United Cerebral of Pennsylvania (UCPA).

Spreat, S. (2019a). Revenue and Expenses over Five Years in Intellectual Disability Service Providers in Pennsylvania. Disability, CBR \& Inclusive Development, 29, 98-108. https://doi.org/10.5463/dcid.v29i4.797

Spreat, S. (2019b). Pennsylvania Direct Support Professional Wage Study. Langhorne, PA: Alliance of Community Service Providers (ACSP), Moving Agencies toward Excellence (MAX), Pennsylvania Advocacy and Resources for Autism and Intellectual Disability (PAR), Rehabilitation and Community Providers Association (RCPA), Arc of Pennsylvania (Arc/PA), The Provider Alliance (TPA), United Cerebral Palsy of Pennsylvania (UCPA).

Spreat, S. (2020). Crises in Intellectual Disability. London: Cambridge Scholars Publish- 
ing.

Spreat, S., Brown-McHale, K., \& Walker, S. (2017). PAR 2015 Direct Support Professional Wage Study. Journal of Public Health Policy and Planning, 1, 50-55.

Torres, N., Spreat, S., \& Clark, M. (2017). Direct Support Professional Compensation Practices: Implications on Service Quality; Tax Dollars; and Quality of Life. Social Innovations, 32, not paginated. 